Antipsychotics, cognitive decline and death in Alzheimer's disease

\section{Antipsychotics, cognitive decline and death in Alzheimer's disease: the London and South-East Region Alzheimer's Disease longitudinal study}

\section{Ames}

The LASER-AD study provides limited reassurance in relation to the occasional prescription of novel antipsychotics to elderly people with dementia

$\mathrm{F}$ or psychiatrists in the business of helping old people who exhibit delusions and challenging behaviours related to dementia, it will be a relief to read some good news at last. Apparently, even if we may not be helping old people with dementia very much when we treat them with an atypical antipsychotic, ${ }^{1}$ we may after all not be hastening their deaths or irreversibly worsening their cognitive function at the same time. In their paper, Livingston et al (see $p$ 25) report that in an epidemiologically representative cohort of 224 people affected by Alzheimer's disease, the consumption of antipsychotic drugs did not correlate with more rapid cognitive decline over a 6month period, nor did people taking antipsychotics have a higher death rate than those who were not prescribed such drugs, once age and severity of dementia were taken into account. The study had robust methods and its results in relation to cognitive decline are based on repeated assessments with a variety of wellaccepted cognitive measures.

Of course it is true that too many old people with dementia are treated too often and for too long with antipsychotic drugs, ${ }^{1}$ and efforts to diminish the prevalence of such prescriptions is to be greatly applauded, but the merit of the London and South-East Region Alzheimer's Disease study is in examining in an everyday context the potential negative consequences of novel antipsychotic use, which have caused great concern in recent years. As a coauthor of the paper $^{3}$ that prompted the original panic over novel antipsychotics and the putative risk of stroke in people with dementia $^{1}$ (if we had never conceived our investigator-initiated study, concerns about risk of stroke in people with dementia prescribed antipsychotics might not have surfaced for years to come), I am relieved to find that my inability to manage every single person I see with dementia and distressing ideas, or severe aggression that puts other frail old people at serious risk, without occasional use of a novel antipsychotic drug in an $\mathrm{n}=1$ trial, may not be wholly irresponsible.

J Neurol Neurosurg Psychiatry 2007;78:2. doi: 10.1136/jnnp.2006.100586

Correspondence to: D Ames, Academic Unit for Psychiatry of Old Age, Department of Psychiatry, University of Melbourne, Normanby House, $\mathrm{St}$ George's Hospital, 283 Cotham Rd, Kew, Victoria 3101, Australia; dames@unimellb.edu. au

Competing interests: DA has received research support, assistance to attend conferences, and honoraria for lectures and consultancy services from companies which market antipsychotic drugs, including Astra Zeneca, Bristol Myers Squibb, Eli Lilly, Janssen Cilag, Novartis and Pfizer.

\section{REFERENCES}

1 Ames D, Ballard C, Cream J, et al. For debate: should novel antipsychotics ever be used to treat the behavioral and psychological symptoms of dementia (BPSD)? Int Psychogeriatr 2005; 17:3-29.

2 Livingston G, A E Walker, C LE Katona, C Cooper, et al. Antipsychotics and cognitive decline in Alzheimer's disease: The LASER-AD longitudina study. J Neurol Neurosurg Psychiatry 2006;78:25-9.

3 Brodaty H, Ames D, Snowdon J, et al. A randomized placebo-controlled trial of risperidone for the treatment of aggression, agitation and psychosis of dementia. J Clin Psychiatry 2003:64:134-43.

\title{
Behavioural and psychological symptoms of dementia associated with Parkinson's disease
}

\section{Leroi, A Burns}

\section{Assessment of behavioural and psychological symptoms is important in brain disorders}

$\mathrm{T}$ he recognition that psychiatric symptoms and behavioural disturbances are important in organic brain disorders has grown inexorably over the past 15 years. Their contribution to carer stress and institutionalisation is well recognised. ${ }^{1}$ More specifically, in Parkinson's disease, researchers are becoming increasingly aware of the need to include the assessment of behavioural and psychological symptoms as important outcome measures in clinical trials, and clinicians are starting to recognise the need to identify and manage these symptoms in addition to focusing on the motor symptoms and their complications.

The study by Aarsland et al in this issue ${ }^{2}$ (see $p$ 36) reports the results of a cluster analysis of the symptoms in a larger study in people with dementia associated with Parkinson's disease, ${ }^{3}$ using the gold standard of the assessment for neuropsychiatric symptoms, the Neuropsychiatric Inventory. ${ }^{4}$ The findings support the fact that these symptoms are common in Parkinson's disease (89\% had at least one symptom, and $77 \%$ had two or more). The most common symptoms were depression, apathy, anxiety and hallucinations (in this order, all with rates of between $44 \%$ and $58 \%$ of patients). Five clusters were identified and shown to be related to other aspects of dementia (in particular, psychosis/agitation was associated with carer distress, cognitive impairment and Parkinsonian signs).

The population-based Cache County Study of Memory in Ageing, ${ }^{5}$ focusing 